Alfredo Joignant, Acting Politics. A Critical Sociology of the Political Field (Nueva York y Abingdon, UK: Routledge, 2019).

RESEÑA

\title{
ACTUANDO LA POLÍTICA
}

\author{
Carlos Peña \\ Universidad Diego Portales
}

[ 1 título de este libro —Acting Politics. A Critical Sociology of the do teórico que en sus páginas se despliega. En él, en efecto, se trata de describir a la política como un quehacer que carece de sustancia, de algo que permita definirla con prescindencia de su situación temporal. La política, sugiere en efecto este libro, se constituye performativamente, mediante la actuación de los actores que la ejecutan.

La pregunta por lo que constituye a la política, o, mejor aún, la pregunta por qué es lo que hace a un político — central en el argumento de este libro_- es de las preguntas más recurrentes y más viejas de la literatura. Se la encuentra en Platón, quien insinúa que el político es un especialista en la crianza de hombres, una frase que no molestaría a los teóricos de la biopolítica; en Aristóteles, que la trató en dos de sus obras más importantes: la Ética nicomaquea y la Política; en Cicerón, quien describe en sus discursos al político como el piloto que conduce la nave del Estado, aunque Estado no tenía aún el sentido moderno que hoy posee; en Santo Tomás, en su opúsculo Del gobierno de los prín-

Carlos Peña. Abogado y doctor en filosofía por la Universidad de Chile. Profesor asociado de esa institución. Rector de la Universidad Diego Portales. Sus más recientes libros son El tiempo de la memoria (2019), Por qué importa la filosofia (2018) y Lo que el dinero sí puede comprar (2017). Email: carlos.pena@udp.cl.

${ }^{1}$ Alfredo Joignant, Acting Politics. A Critical Sociology of the Political Field (Nueva York y Abingdon, UK: Routledge, 2019). 
cipes, cuya tarea dice es inteligir racionalmente el bien común; en Maquiavelo, en Ribadeneyra, incluso en Azorín; hasta alcanzar a Schmitt, Strauss, Voegelin o Arendt en el pensamiento continental. En toda esa vasta literatura se intenta inteligir en qué consiste la arena de la política y cuáles son los atributos y características del político. Si acaso es la razón como creen Platón o Tomás, o la fortuna como piensa Maquiavelo, o un sentido práctico como el que describe Kant en la Crítica del juicio, según sugiere Arendt.

Alfredo Joignant, y he aquí la originalidad de su planteamiento, y el valor de su libro, piensa que lo político es un quehacer que no puede ser definido con prescindencia de la escena en que se desenvuelve.

El suyo es un intento por sentar las bases de una teoría general del quehacer político a partir de la sociología de Bourdieu, empleando, en especial, los conceptos de campo, habitus y capital. Cada uno de los capítulos del libro está destinado a esclarecer, echando mano a investigaciones realizadas por el propio autor, ese aparato teórico con el que, inspirado en Bourdieu, Alfredo Joignant intenta construir una teoría general de la política. Se trata, como se ve, de un proyecto intelectual de amplias proporciones que el trabajo previo del profesor Joignant — por ejemplo, sus trabajos sobre élites y technopols - ya insinuaba.

Si hemos de resumir la importancia de este trabajo, debemos decir que él intenta proveer una teoría de largo alcance que permite conferir sentido a la recolección de datos y las interpretaciones puramente estratégicas con las que suele interpretárselos, que son hoy día tan frecuentes en la ciencia política, para en cambio favorecer una comprensión (verstehen, según la fórmula que viene de Dilthey) del quehacer político que logre capturar el sentido que en cada caso él inevitablemente posee. Así, emplear la noción de campo supone darse a la tarea de recolectar datos - por ejemplo empíricos - y al mismo tiempo captar el horizonte de sentido en cuyo interior se configuran.

Ahora bien, a fin de formular algunos comentarios al trabajo del profesor Joignant, puede ser útil dividirlos en tres partes. En la primera, examinaré el enfoque que emplea y las particularidades que posee; en la segunda parte, revisaré en términos muy generales las fuentes de las que se nutre, y en la tercera parte, discutiré los límites de un enfoque como el que en este libro se adopta. 
En la tradición del pensamiento político es frecuente situar al quehacer político como el manejo de un espacio dotado de identidad ontológica, como ocurre por ejemplo en Santo Tomás o el Padre Ribadeneyra; o, en cambio, como un simple juego de agencia y de incentivos, como es frecuente encontrar en cierta literatura del public choice; o como un ámbito agonal, como es el caso de los análisis inspirados en Carl Schmitt; o como una cuestión de estructuras, como ocurre, por ejemplo, con los análisis del tipo de Althusser; o, incluso, como una cuestión de personalidades, como ocurre con el estudio de Ortega sobre Mirabeu.

Ahora bien, el enfoque que adopta el profesor Joignant en este libro no coincide con ninguno de ellos, puesto que, siguiendo a Bourdieu, define lo político como un quehacer cuya fisonomía y cuyo sentido sólo pueden ser inteligidos escudriñando, hasta develar, la red de relaciones en cuyo interior se produce. Se trata de un enfoque hasta cierto punto circular, puesto que el campo político, al consistir en una red de relaciones, no podría ser identificado con prescindencia de ellas, y éstas, por su parte, no podrían ser distinguidas de las pertenecientes a otros campos sin contar antes con alguna idea de aquello en que lo político consiste. Pero esta circularidad del planteamiento no es un defecto, sino una condición de este tipo de investigaciones. Después de todo, ya Durkheim, cuando inauguró la sociología, dijo que ésta debía explicar "lo social por lo social".

Ahora bien, una vez que el campo político se describe como un sistema de posiciones sociales, en el que cada una de ellas determina por su relación con todas las demás, de manera que el campo político semeja un campo de fuerza en el que cada punto es sostenido por vectores invisibles, quedan también definidos los otros conceptos, en especial el de capital, al que el profesor Joignant dedica algunas de sus mejores páginas.

Conviene detenerse en los conceptos que este libro utiliza a fin de asomarse a la perspectiva general que, mediante ellos, logra construir.

El capital es, en principio, una dotación cualquiera que carece de valor intrínseco. Su valor es en realidad equivalente a lo que desde Aristóteles a Marx se llama valor de cambio. El valor de cambio es 
asignado por el sistema de relaciones que constituyen el campo, un sistema de relaciones que varía, desde luego, históricamente. Así entonces qué sea el capital político, cuál la dotación precisa que lo constituye, no podría ser definido con prescindencia de una red de relaciones sociales.

Estrechamente enlazado con el capital, se encuentra el concepto de habitus, que proviene de la vieja noción aristotélica de hexis. En Aristóteles, según puede leerse en la Metafísica, hexis equivale a la vez a una energía y una disposición. Bourdieu emplea el concepto para aludir a un sistema de competencias en el sentido de una capacidad para la acción que es socialmente reconocida como tal capacidad.

Todos esos conceptos, el de campo, el de habitus y el de capital, carecen de garantía ontológica y se configuran históricamente, de manera que $-\mathrm{y}$ el profesor Joignant insiste una y otra vez en el punto para que no quede duda - el análisis político es inseparable de la temporalidad o, mejor aún, de la historicidad que lo constituye. Lo que ayer formó parte del capital político, o aquella disposición que se incorporó como habitus - por ejemplo, el linaje en el primer caso o la elocuencia en el segundo- pueden ser despojados de valor por los vientos de la historia, de manera que pensar la política es pensar también históricamente.

Pero no es sólo la ontología o la idea de que la política posee un piso ontológico en medio del que se desenvolvería, como si la política estuviera anclada en la naturaleza, lo que este libro de Joignant echa por tierra, sino que también relativiza la tarea normativa que a la política suele asignársele.

Suele sostenerse, en efecto, que la política y el político deliberan la forma en que la realidad pueda llegar a ser lo que debe ser. Según este punto de vista, la política sería un instrumento para que la verdad normativa llegue al mundo. Joignant, como Arendt, piensa que la verdad nada tiene que ver con la política y, por lo mismo, las ideas cuando tienen éxito, más que acertar, es que logran transformar performativamente el campo en el que inciden. En el capítulo sobre el papel de las ideas, uno de los capítulos, en mi opinión, mejor logrados del libro, Joignant muestra, con acopio de antecedentes y de ejemplos, que las ideas en política no son un espacio traslúcido cuya medida sea la verdad. 
II.

El enfoque que acabo de describir tiene un muy conspicuo origen que, por supuesto, está a las espaldas de Bourdieu.

Sus primeros signos se encuentran en una investigación que llevó adelante Ernst Cassirer, el gran neokantiano, famoso por su disputa con Heidegger, acerca de las formas simbólicas, uno de esos trabajos que acerca hasta casi la intimidad a la filosofía con la sociología. Cassirer sugirió que nuestras capacidades cognitivas son, al mismo tiempo, configuradoras del mundo. Nunca aprehendemos el mundo tal cual es, sino que siempre lo atrapamos mediado por alguna forma que lo envuelve y sin la cual se nos escaparía. De ahí, dijo Cassirer - y habría bastado esta observación para que se le recordara-, que toda crítica de la razón es al mismo tiempo una crítica de la cultura. Este punto de vista, de fuertes raíces neokantianas como se ve, presenta la cultura como un ámbito de significados que se han ido poco a poco adosando a nuestra experiencia sensible, hasta que la relación entre lo interno y lo externo principia a carecer de importancia.

Por supuesto, Bourdieu conoció el trabajo de Cassirer e influyó sin duda en su idea de contar con una armazón teórica que le permitiera superar la vieja querella de las ciencias sociales entre agencia y estructura, o aquella que es posible observar entre el realismo de la estructura y el realismo de la acción. ¿Es el agente y sus capacidades quien tiene la última palabra en la vida social o es la estructura la que la posee? Bourdieu sostiene que el dilema es erróneo, porque la agencia es moldeada por la estructura y viceversa, y la tarea del cientista social es describir la manera en que ello ocurre, eludiendo cualquier perspectiva sustancialista, cualquier punto de vista que suponga que la vida social se erige a partir de una esencia preconstituida.

Haciendo pie en esos puntos de vista - que en la literatura filosófica son hoy frecuentes, como ocurre en la filosofía de la acción inspirada en Austin o Wittgenstein - el profesor Alfredo Joignant intenta llevar a término, de forma sistemática, una concepción que, por decirlo así, se aleje por igual del operacionalismo (que tiende a reducir lo político a la medición de sus acciones) y del sustancialismo (que ve en lo político una realidad ontológica o quiescente). La concepción que Joignant expone en este libro es una concepción relacional de la política, cuya mejor metáfora, que el título del libro insinúa, es la del juego. 
El juego ejemplifica muy bien la realidad social y, por extensión, la realidad de la política. El juego, en efecto, es una realidad convencional, opuesta a la natural, en la que se entrelazan reglas y acciones hasta configurar poco a poco una práctica que es, a fin de cuentas, la realidad del caso. Ésta es una vieja idea que está en Kant, quien en su antropología habla del "juego de la vida"; en Heidegger, en sus cursos de los años treinta sobre introducción a la filosofía, y por supuesto en Wittgenstein, con la idea de juegos de lenguaje. El empleo de la noción de juego, o, como prefiere el título de este libro, la idea de que la política se actúa, subraya con gran brillo esta concepción no sustancialista, histórica y relacional de la política que, inspirándose en Bourdieu, el profesor Joignant despliega en este libro.

Todos los conceptos cuyo origen acabo de mencionar no son exactamente sistematizados por Alfredo Joignant en este libro, sino que son más bien mostrados por la vía de examinar su funcionamiento. Desde ese punto de vista, el libro ejecuta muy bien la convicción de que la mera teoría no es posible, porque toda teoría que lo es realmente está enlazada con la práctica. El libro piensa la política sin pensar políticamente, y ejecuta la teoría sin reflexionar teóricamente.

III.

¿Tiene limitaciones este enfoque? Hay algunas que saltan a la vista y que, en vez de ser obstáculos, son desafíos que un programa de investigación, como el que Alfredo Joignant está desenvolviendo, debe ser capaz de disolver. Las principales en mi opinión son las tres que siguen.

Desde luego el enfoque relacional debe hacer frente a lo que, desde antiguo, desde los trabajos de Dilthey para ser más preciso, se llama "círculo hermenéutico". Si lo político es un campo de meras relaciones sin sustento ontológico alguno, entonces ¿cómo se identifica enfrente de otras relaciones? Esta objeción no es sin embargo tal. El círculo hermenéutico es la condición misma de las ciencias sociales, condenadas a tratar con un objeto a partir de una noción que es fruto de la misma práctica que se intenta identificar. Esto es lo que Durkheim, como anoté más arriba, reconoce en su famosa máxima, tantas veces malentendida, según la cual lo social se explica por lo social. 
A lo anterior se suma el planteamiento de Cassirer respecto a la medida del éxito o la validez de una descripción en un determinado campo simbólico. ¿Cuál es la medida del rigor de estas descripciones? Alfredo Joignant, a juzgar por los ejemplos que su libro contiene, intenta eludir, tal como lo haría Bourdieu, la oposición entre el empirismo positivista y la simple comprensión de los fenómenos. Como se sabe, hay una larga disputa en las ciencias sociales que opone la descripción fáctica de los fenómenos, entregada a métodos empíricos, por una parte, y la comprensión, que consistiría en un esfuerzo por captar el horizonte de sentido que posee la conducta que se describe, por la otra. Para Joignant, siguiendo a Bourdieu, esos extremos pueden ser conciliados: la validez de la descripción del campo político exige datos que sean significativos a la luz de una cierta comprensión del campo, y esta última, por su parte, requiere datos que la hagan plausible. En otras palabras, los datos deben ser relevantes a la luz de un cierto horizonte de sentido que el investigador debe suponer, y este horizonte, a su vez, consistente con los datos que se recopilen.

La tercera es el peligro del irracionalismo o, si se prefiere, del relativismo. Si las ideas, como se sugiere en este libro, valen por su poder performativo y no por su contenido conceptual, ¿cómo evitar considerar la vida social y la política como un baile de máscaras? Quizá aquí habría que echar mano a la vieja distinción — que está en autores tan disímiles como Bergson o Wittgenstein - entre el punto de vista interno a una práctica social y el punto de vista externo. El sociólogo o el cientista político, como es el caso de Alfredo Joignant, adoptan un punto de vista externo a la práctica social, y por eso son capaces de apreciar la contingencia de las ideas que allí se desenvuelven. Otra cosa ocurre cuando se adopta el punto de vista interno a la práctica, el punto de vista de los actores: en ese caso, la contingencia desaparece. El problema entonces, el viejo problema de las ciencias sociales, el problema que Weber sospechó cuando reclamó la neutralidad de la ciencia, se configura cuando una misma persona intenta adoptar ambos puntos de vista, porque, en ese caso, como observador sabe que todo es contingente, y como partícipe está convencido de que hay cosas cuyo valor es necesario. Lo que parece más difícil, entonces, es saber que todo es contingente y pretender a la vez que hay valores necesarios. Es lo que le ocurre al científico que, al mismo tiempo, participa de la política. EP 